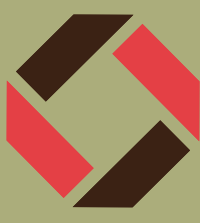

\section{A gift of glass}

web.mit.edu/glasslab

\section{Zenzile Brooks}

W e are taught as children that it is impolite to return a gift. However, the chaotic lab space that sprawled before junior faculty member Michael Cima in January 1986 was surely the exception to this social rule.

A senior faculty member retiring from the Massachusetts Institute of Technology (MIT) had offered Cima a basement laboratory that had been unused for several years, and Cima had accepted with neither hesitation nor observation. After the blaze of finals subsided, local artist Page Hazlegrove and a few students asked Cima if they could use the furnace in his new laboratory for glassblowing. Cima agreed - still without observation.

On a chilly January day, Cima popped down to the lab to finally observe the spoils, and could not believe his eyes. "There was asbestos everywhere. Half the lab you couldn't go in, because it was just piles of junk. There was this big pile of bricks. There were a couple of guys there with no shirts on, pulling out gobs of glass. The windows were wide openJanuary. I looked, and I said, 'Oh my god, they're going to kill themselves."'

Over the next year, Hazlegrove would lure Cima into the thrilling art of glassblowing. This tiny glass lab would be rescued from a period of dormancy, and restored for all students. Cima himself would help to clean the lab, get rid of that pile of bricks, build furnaces, and eventually teach the craft. Cima would discover the power of glassblowing to train MIT students in essential skills for research, science, and engineering.

Any glassblowing operation requires a team of people, a few-foot long pipe, and a $2000^{\circ} \mathrm{F}$ furnace containing molten glass. The team thrusts the pipe into the furnace to gather molten glass from within. Over the course of an hour or so, they carry the loaded pipe back and forth between the furnace and tools seemingly pilfered from a medieval torture chamber-wiry pincers, glistening knives, giant brushes, a shiny steel table. Periodically, one member will sit down and roll the pipe back and forth across raised metal arms at lap height, while the second member crouches down and blows the pipe to inflate the sagging molten glass on the other end. The piece responds just like some heavy, glowing balloon; the hot glass gives off an orange luster that mimics the fiery red of the furnace.

Sophie Diehl, a junior in electrical engineering, said her favorite aspect of this dance is "the way the glass looks when it's still hot. That's something that you don't get to see unless you're actually in the Glass Lab. Any piece that looks beautiful at room temperature looks even more beautiful at $1500^{\circ}$ [Fahrenheit]. It just has this special way of glowing from the inside that is really enthralling."

The Glass Lab glows with activity most days of the year. There are over
100 applicants for the mere 16 student spots per class each semester. A team of 50 students, staff, and instructors run the programs. Famous artists such as Dale Chihuly are invited for the artist-in-residence program or to present the annual Page Hazlegrove Lecture (established in memory of the artist who passed away in 1997). Local junior high school students visit in the summer.

Glass Lab students acquire two sets of skills essential for a career in science, technology, engineering, and mathematics (STEM). First, they gain a personal understanding of basic materials properties. As instructor Peter Houk said, "You really need to understand the material, or it will break and crack and not forgive you." Glass has a heady mix of materials properties - poor fracture resistance, various thermal expansion coefficients, a range of stiffnesses and viscosities - and students must intuitively understand each property as they work with the glass. Blow the piece up too much and it's too thin to work, warns Diehl. Forget to heat the bottom and it cracks.

MIT alum Kaitlyn Becker recalls more than one occasion when her Glass Lab experience came to play on an exam. "I could sit down, in a test, and if I wasn't quite sure that I had the right answer, say for a thin-walled pressure vessel, I imagined myself sitting at the bench, playing with my [glass] bubble, poking it and prodding it, or heating it up or cooling it

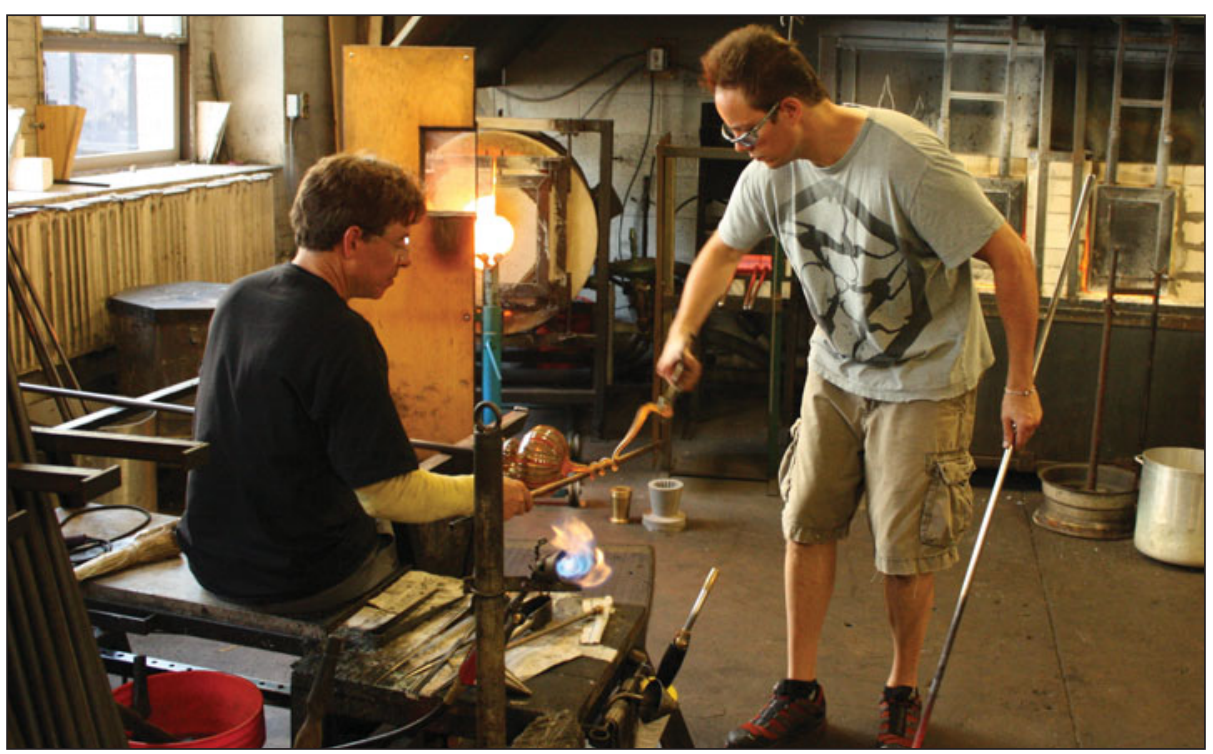


down," said Becker. "And then I could think about how my bubble would behave, and then look at the equations that I was writing, and see if they matched what I would expect to see while I was at the bench." Becker developed a powerful physical intuition of thermodynamics, fluid dynamics, and mechanics of materials.

Second, Glass Lab students develop essential teamwork and communication skills. As the young Michael Cima stood blinking in that bustling lab space in 1986, he had a realization. "It sort of struck me that here's a craft art that you don't do by yourself, you have to do with somebody else. And more importantly, you have to improvise with somebody else. And that is the key experience-the whole glass program is designed around that."

In order to successfully create a piece, team members must talk, think, and listen to each other. They must anticipate when their teammate will complete Part A so they can connect it with Part B. Teams that build Boeing jets, skyscrapers, and supercomputers employ these same collaboration skills. Mechanical engineering graduate student Patrick Barragan corroborates the industrial

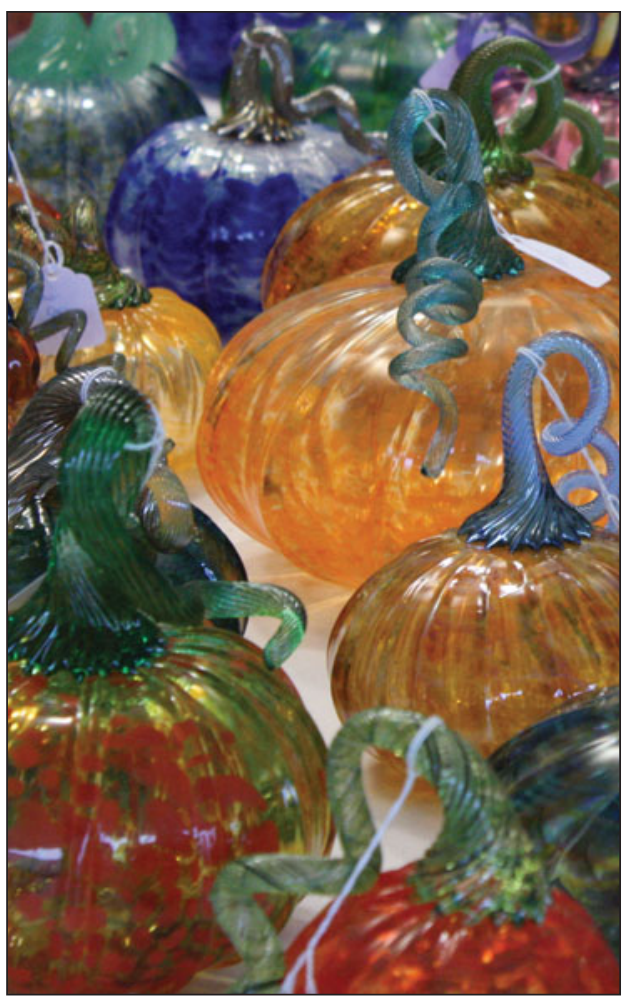

preparation students get from the Lab. "Whenever you're working anywhere else-if you're working in a research lab, if you're coaching a team, if you have an industry job - generally everybody is going to have to work in teams. [In the Glass Lab] you get to practice that dynamic where everybody understands that they're all responsible for some part of the system, and they have to do their job, and they have to do it well, such that the final product can be good."

The teamwork and communication aspects of the Glass Lab are two huge reasons for its existence at a renowned technical institution like MIT. When Cima realized the potential of glassblowing to train MIT students in these essential STEM skills, he asked the then Dean of Engineering Gerald Wilson for the funds and permission to get the laboratory off the ground. At the time, the United States was watching a lot of jobs, especially in manufacturing, slip overseas. MIT responded by changing its curriculum, creating new laboratory courses, and finding new ways to learn. Glassblowing was a unique, teamworkfocused extracurricular activity that aligned with the shifting curriculum of MIT. Cima recalls that Wilson agreed to fund the lab on one condition: that the first renovation would be to change the then-translucent corridor windows into clear glass. This would allow an additional team member - the curious passerby - a chance to partake in the process. Cima heartily agreed.

The similarities between glassblowing and Boeing-747-building don't stop at teamwork and communication, however; both processes also require money. The Lab sustains itself through the sale of glass pumpkins, which all Lab students help create. Once a year, the local Boston and Cambridge communities flock to MIT for the Great Glass Pumpkin Patch. Hundreds of customers are assigned a number and patiently wait in line to be called. When they are, they walk (no running, please) to tables overflowing with glass pumpkins of all shapes and sizes - tiny purple ones you can hold in one hand, large green and gold ones you must carry with a buddy.

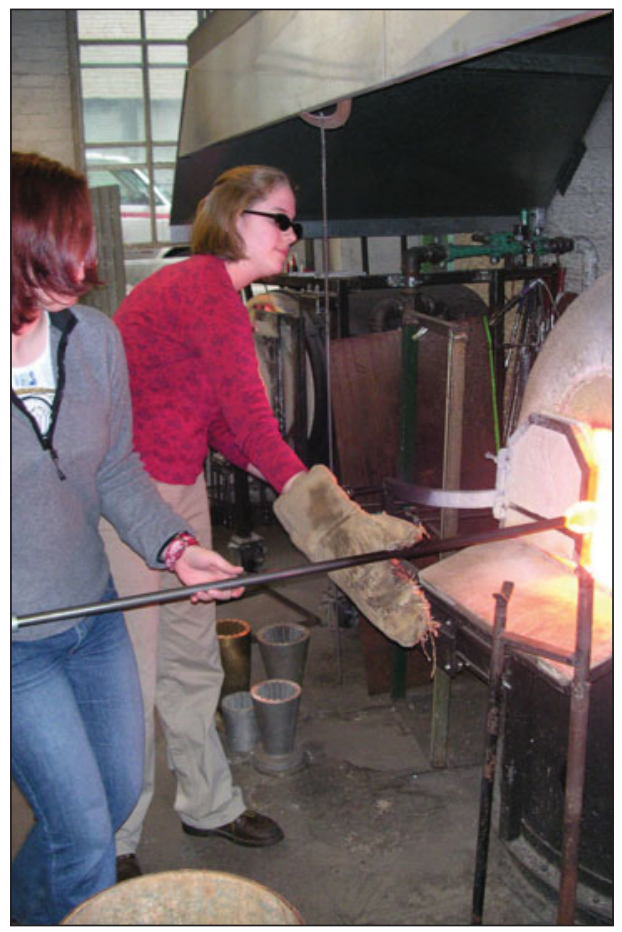

The funds from this sale support laboratory activities throughout the year.

Outside of this special weekend, however, the Lab is a highly constrained resource. Many applicants never receive a coveted spot, and the Lab shares a room with blacksmithing classes. Fortunately, the Glass Lab has recently developed a plan to double its size. Project goals include moving the laboratory across the hall to its own room and doubling the size of the beginner program.

Houk would also like to maintain the carbon footprint of the current lab, despite the expansion, and has come up with a creative way of doing so: incorporating "right-sized" furnaces that can be used for any combination of student groups. The existing laboratory includes one large monster of a furnace, which can take nearly a week to preheat and is turned off only once or twice a year for cleaning. Since the Lab caters to beginners who make small pieces, the new design will incorporate many small furnaces, which use a quarter of the typical gas, are more easily powered off, and can nicely reheat small pieces without wasting space.

The future of this humble basement shop glows as bright and hot as a heap of molten glass fresh from the fire. 


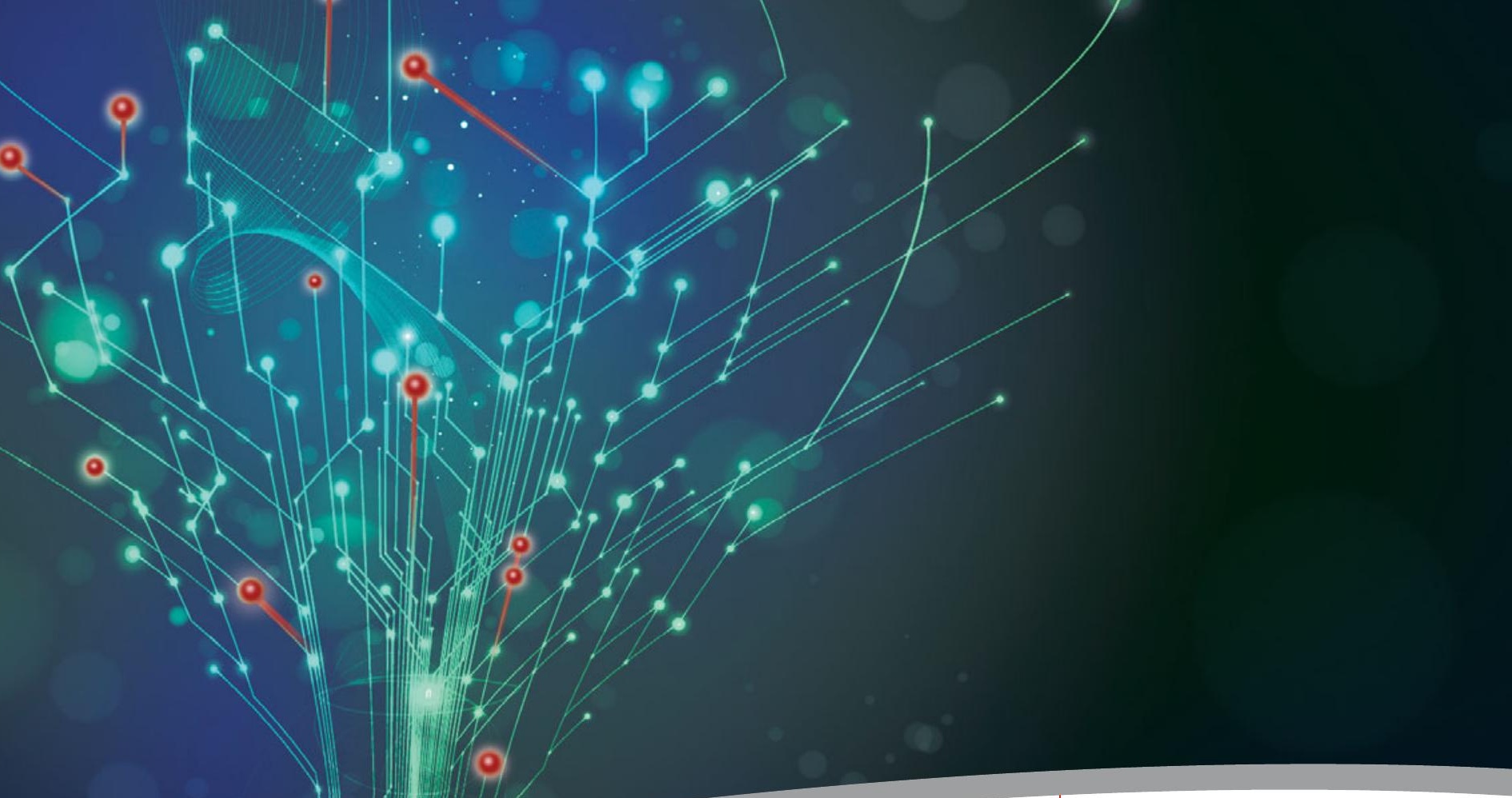

\section{Deposition Materials for Energy and Electronics}

From Aldrich ${ }^{\circledR}$ Materials Science

\section{MOCVD/ALD Precursors}

- Prepackaged cylinders for direct use in deposition systems

\section{PVD Materials \& MBE Crucibles}

- High purity sputtering targets, evaporation slugs, metal foils and MBE Crucibles

\section{Solution Deposition Materials}

- Metal and silicon based precursors

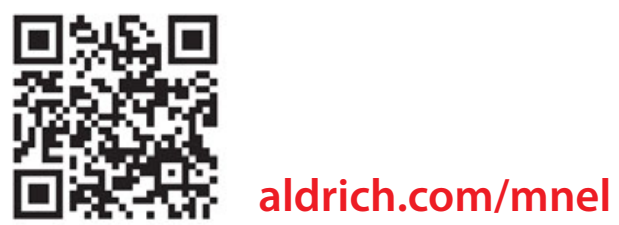

\section{(A) $A L \underset{\text { materials scienne }}{\operatorname{Rin}}$}

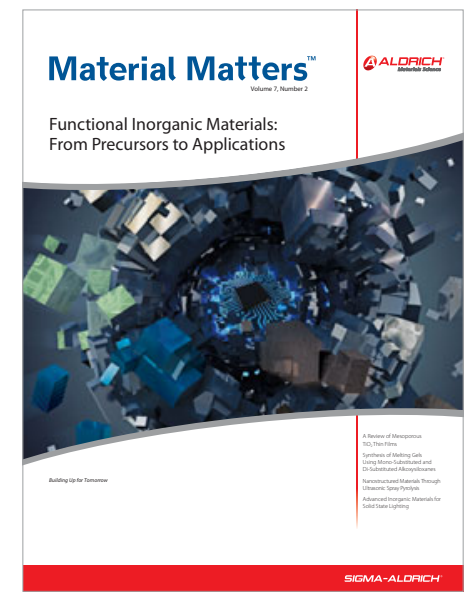

Subscribe (free) to: Material Matters ${ }^{\mathrm{TM}}$ aldrich.com/mm 